This article was downloaded by:[University Library Utrecht]

On: 25 January 2008

Access Details: [subscription number 789271090]

Publisher: Routledge

Informa Ltd Registered in England and Wales Registered Number: 1072954

Registered office: Mortimer House, 37-41 Mortimer Street, London W1T 3JH, UK

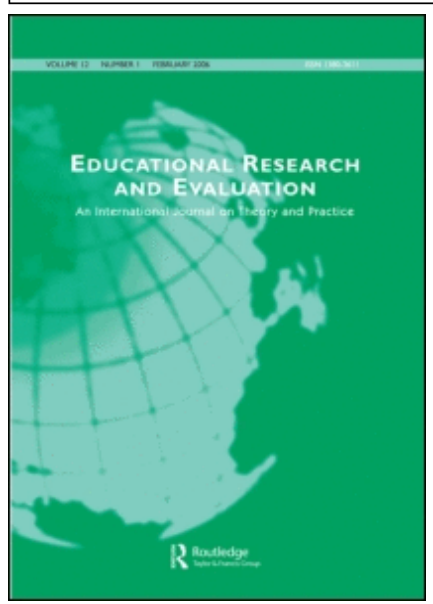

\title{
Educational Research and
} Evaluation An International Journal on Theory and Practice

Publication details, including instructions for authors and subscription information: http://www.informaworld.com/smpp/title content=t714592776

The gap between research and practice revisited

Fred A. J. Korthagen ${ }^{a}$

a Vrije Universiteit Amsterdam, The Netherlands

Online Publication Date: 01 June 2007

To cite this Article: Korthagen, Fred A. J. (2007) 'The gap between research and practice revisited', Educational Research and Evaluation, 13:3, 303 - 310

To link to this article: DOI: $10.1080 / 13803610701640235$

URL: http://dx.doi.org/10.1080/13803610701640235

\section{PLEASE SCROLL DOWN FOR ARTICLE}

Full terms and conditions of use: http://www.informaworld.com/terms-and-conditions-of-access.pdf

This article maybe used for research, teaching and private study purposes. Any substantial or systematic reproduction, re-distribution, re-selling, loan or sub-licensing, systematic supply or distribution in any form to anyone is expressly forbidden.

The publisher does not give any warranty express or implied or make any representation that the contents will be complete or accurate or up to date. The accuracy of any instructions, formulae and drug doses should be independently verified with primary sources. The publisher shall not be liable for any loss, actions, claims, proceedings, demand or costs or damages whatsoever or howsoever caused arising directly or indirectly in connection with or arising out of the use of this material. 


\title{
COMMENTARY ARTICLE
}

\section{The Gap Between Research and Practice Revisited}

\author{
Fred A. J. Korthagen* \\ Vrije Universiteit Amsterdam, The Netherlands
}

\section{A Perennial Problem}

The important initiative of bringing together six contributions from various countries, with the aim to restart an in-depth analysis of the relation between educational research and educational practice, fits into a global trend. Increasingly, teachers - but also parents and politicians-voice dissatisfaction with the divide they experience between research and practice and the resulting minimal impact of teacher education (Ashton, 1996; Barone, Berliner, Blanchard, Casanova, \& McGowan, 1996). The problem seems to be perennial. Already more than a century ago, John Dewey pointed at a gap between theory and practice in education (Dewey, 1904), and he discussed possible approaches to bridging this gap (see also Shulman, 1998). During the 20th century, the focus was often on the question of how practice can be better linked to valuable research outcomes. To date, attention is more focused on how research outcomes can be better linked to practice. Probably, this has to do with the fact that all the attempts at enhancing the dissemination of research results have not led to a clear, successful, and generally accepted approach to bridging the research-practice divide and that, despite all these attempts, the gap between research and practice seems to have increased rather than diminished during the second part of the 20th century.

Each of the six contributions to this special issue offers interesting perspectives on this gap. In this concluding reflection, I will discuss a few issues emerging from a consideration of the combined contributions. Next, I will proceed to the question of what we can learn from this special issue regarding possibilities for bridging the gap.

\footnotetext{
*Centre for Educational Training, Assessment and Research (CETAR), Vrije Universiteit, De Boelelaan 1105, 1081 HV Amsterdam, The Netherlands.

Email: f.korthagen@uu.nl
} 


\section{The Emerging Picture}

An issue that prominently emerges from the six articles is that the gap between research and practice is most of all a gap between professional cultures and that there is a strong need for researchers and practitioners to build joint communities, bringing together both a research and a practical focus. Although their approaches may differ, the thinking of the authors in this special issue thus concurs with recent developments in educational psychology, in which learning communities and collaborative or cooperative learning structures are increasingly considered important avenues towards deeper level learning. In this respect, there seems to be a clear common thread in this special issue.

However, when reading the articles more carefully, different ways of framing the problem are clearly visible. This fits in with the remark made in the contribution by De Vries and Pieters, that even within the research community itself collaboration is lacking. And indeed, one can see this when looking at the six contributions. Although each puts forward interesting and important perspectives on the gap between research and practice, and although at a superficial level one can see all kinds of parallels between the contributions, their concepts, language, and ways of looking at the problem are rather different. On the one hand, this has the advantage of a broad picture being presented; on the other, it reveals how complex the issue is and how difficult it is to develop a common frame of reference that can support a joint tackling of the problem.

And even the broad picture already displayed by the various authors can be further complemented, for there are a number of other important perspectives on the research - practice divide that can be found in the literature and that were only briefly or not at all touched upon in the contributions to this special issue. I will discuss some of these additional perspectives in the next section.

\section{Other Causes of the Gap}

One cause-often mentioned in the literature on teacher education - has to do with teachers' prior knowledge, which, according to many researchers, plays a powerful role in learning (Wubbels, 1992). Teachers' preconceptions show a remarkable resistance to change (Joram \& Gabriele, 1998). This can in part be explained by their firm roots in the many years of experiences that teachers themselves have had as pupils within the educational system (Lortie, 1975). Preconceptions also shape the way new knowledge is being understood. Stofflett and Stoddart (1994), for example, argued that teachers' conceptions of how subject matter should be taught are strongly influenced by how they themselves learned the subject content (see also Huibregtse, Korthagen, \& Wubbels, 1994). This means that whatever "solution" or combination of approaches we may devise for bridging the gap, we will have to face a basic lack of flexibility inherent to human nature.

The human factor also implies that we cannot understand practice and the transfer problem by merely taking a cognitive stance. Although Broekkamp and 
Van Hout-Wolters did briefly mention this point, I think it needs more attention if we wish to deepen our understanding of the gap. Teaching is a profession in which feelings and emotions play an essential role (Hargreaves, 1998a; Nias, 1996), but "the more unpredictable passionate aspects of learning, teaching and leading (...) are usually left out of the change picture" (Hargreaves, 1998b, p. 558). The problem of promoting fundamental professional change is first of all a problem of dealing with the natural emotional reactions of human beings to the threat of losing certainty, predictability, or stability. This issue seems to be somewhat undervalued in the six contributions as a whole.

We can elaborate on the human aspect even further. Many authors emphasize that the person of the learner is an important factor in learning (for an overview, see Korthagen, 2004). Bullough (1997, p. 21) states that "teacher identity-what beginning teachers believe about teaching and learning and self-as-a-teacher - is (...) the basis for meaning making and decision making." This concurs with Day (1999, p. 94), who talks about the "personalized nature of teaching." Bullough (p. 21) adds that the most important learning outcomes in teachers will thus be "personal, idiosyncratic, and probably not measurable." This seems to be an issue which has until recently been rather neglected. It often appears as if external observers are amazed at the fact that teachers do not apply important research insights and translate them into specific behaviors, which from the standpoint of the outsider would be so "logical" to do. However, humans do not act on the basis of logic alone, and from an actor-perspective there are often significant personal reasons for not acting in such a manner. Moreover, experts tend to overlook the fact that human change can take many forms and that teachers may change in ways that are unexpected or not immediately visible to an outsider.

Another cause often mentioned in the literature is the complexity of teaching (e.g., Hoban, 2002; Loughran, 2006). Broekkamp and Van Hout-Wolters also mention this cause briefly in their contribution to this special issue, but I would like to take it a little further. Clark and Lampert (1986, p. 28) state that teachers "are expected to accomplish complex and even conflicting goals. Under these circumstances, a priori knowledge identified by researchers about the relationship among particular decisions or actions and their outcomes is of limited worth". Hoban (2005, p. 9) states: "(....) what a teacher does in a classroom is influenced by the interaction of many elements such as the curriculum, the context, and how students respond to instruction at one particular time." Hoban continues by saying that this view of the nature of teaching necessitates "holistic judgement" (cf. Day, 1999) about what, when, and how to teach in relation to a particular class. Moreover, practice is generally ambiguous and value-laden (Schön, 1983). Robinson (1998) states that in specific educational situations, even experts have different opinions on what is the best way to use theory. Different theories may each have their value in explaining a certain aspect of the situation and hence lead to different perspectives.

The complexity of teaching explains why the problem of the relation between research and practice looks different in disciplines such as medicine and engineering. In many of the contributions to this special issue, such disciplines are considered 
inspiring examples, because the research-practice divide seems to be less manifest in these disciplines. However, there is a risk of oversimplifying things. In these disciplines, problems and solutions are determined less by the complex psychological and sociological phenomena influencing educational processes. This is something we have to bear in mind in order to realize that we cannot simply transfer what works in one discipline to another. In this respect, the Pasteur example often referred to may obscure the underlying problematic issue in education that we mentioned before: the human factor.

Finally, there is one cause of the transfer problem that has drawn so much scholarly attention that all of the next section will be devoted to it.

\section{Forms of Knowledge}

Teachers need prompt and concrete answers to situations giving them little time to think (Eraut, 1995). This type of action-guiding knowledge is rather different from the more abstract, systematized, and general expert-knowledge researchers develop (Tom, 1997). Different terms are used to name this difference, but much used are the concepts of practical knowledge and formal knowledge. According to Fenstermacher (1994), the former type of knowledge develops in teachers by participating in and reflecting on their own actions and experiences; hence it is situated knowledge (Brown, Collins, \& Duguid, 1989). This practical knowledge enables teachers to deal effectively with practical problems. The validity of this knowledge is confined to the type of contexts or situations within which the events occur, and teachers often have difficulty to put it into words. Formal knowledge, or propositional knowledge, is the knowledge produced by conventional research in order to answer a question such as "What is known about effective education?" It meets criteria for reliability and validity and has the potential for generalization. Aristotle already made a similar distinction between these two types of knowledge, which he called phronesis and episteme.

The character of phronesis is more perceptual than conceptual: it-often unconsciously-focuses the attention of the actor in the situation on certain situational characteristics that are important to the question as to how to act in that situation. To put it concisely, episteme aims most of all at helping us to know more about many situations, while the emphasis of phronesis is on perceiving more in a particular situation and find a helpful course of action on the basis of strengthened awareness. The best translation of phronesis may be "practical wisdom". If we combine this discussion on the importance of phronesis with the above discussion on the complexity of teaching, we may realize that what teachers need above all is ways to direct their awareness towards important aspects of the complex teaching situation at hand. Hence, rather than research outcomes, it is a matter of empathy and sensitivity to what happens in human relations that makes the difference.

Robinson (1998) concluded that the value of theory may thus not be to elicit concrete solutions, but to offer ways of perceiving practice. Marton and Booth (1997) arrived at a similar view. They, too, strongly emphasize the role of perception and 
awareness in (professional) learning and argue that, after the intended learning process, "the learner has become capable of discerning aspects of the phenomenon other than those she had been capable of discerning before" (p. 142). In previous work, Marton, Dahlgren, Svensson, and Saljö (1977, p. 23) referred to this kind of learning as "a change in the eyes through which we see the world" and they consider it to be the essence of professional learning. Marton and Booth (1997) added that, through the changed awareness of the phenomenon, the relationship between the person and the phenomenon has changed.

Summing up, an important cause of the limited impact of research may be that researchers focus too one-sidedly on formal knowledge (episteme) and overlook an essential aspect of professional learning, namely the development of perceptual awareness and an individual's way of relating to the world. By doing so, researchers may well create a gap between theory and practice. In this respect, it would be more adequate to speak about the practice - research gap instead of the reverse.

\section{Directions for Bridging the Gap}

What do the six contributions tell us about possible ways of bridging this gap? As observed above, the base line seems to be: Bring researchers and practitioners together and have them cooperate. During recent decades, social constructivist views and the notion of "communities of practice" (Wenger, 1999) have led to approaches that no longer focus on the individual practitioner but consider professional development as strongly intertwined with professional cultures. This perspective concurs with the promising development within teacher education known by the umbrella term Professional Development Schools (PDS; Bullough \& Kauchak, 1997; Darling-Hammond, 1994). The idea is to develop collaborative partnerships between universities and schools, sharing the responsibility for the professional development of prospective teachers. Successful examples show that schools can indeed become hotspots of educational innovation and change, as De Vries and Pieters state in their contribution.

Referring to publications by authors supporting collaboration structures between schools and universities, Furlong et al. (1996) concluded that the PDS approach may finally allow for a real integration of research and practice. However, a warning must be given. Case studies also illustrate serious problems associated with the PDS approach (see Darling-Hammond, 1994). Castle (1997, p. 221) concluded that "many of the problems stem from the reality that change of this nature involves individuals and relationships." Indeed, a prerequisite is the building of strong and long-term partnerships between university faculty and teachers in the schools. The risk is that when a leading person moves to another job, or personal conflicts arise, the whole collaboration structure may collapse.

Other strategies for bridging the gap put forward in the literature are those which put teacher research in the forefront of professional development (Cochran-Smith \& Lytle, 1993; Stenhouse, 1975). If teachers themselves are the ones who do the research, as is for example the case with the trend towards self-study research 
(Loughran, Hamilton, LaBoskey, \& Russell, 2004), the integration of research and practice is taking place within one person.

Finally, many authors claim that the most important factor in promoting the relationship between research and practice is individual coaching or supervision (Korthagen, Kessels, Koster, Lagerwerf, \& Wubbels, 2001; Showers \& Joyce, 1996). The idea is that a good supervisor may be able to effectively connect the teacher's personal experiences in educational settings and his or her present concerns to research outcomes. Although this is a perspective that is first of all grounded in the thinking about teachers' professional development, it may be a fruitful addition to our thinking about ways of overcoming the gap between research and practice.

\section{Towards an Integrated View}

It is now more than a century since Dewey (1904) expressed his concern about this gap. Have we succeeded in finding a solution? Each of the approaches discussed in the six contributions to this special issue, and those summarized in the previous section, has its own merits and seems to solve part of the problem. As Wideen, Mayer-Smith, and Moon (1998), and Hoban (2005) suggested, we need an integrated view in which all the aspects influencing teacher development are taken into account and which combines several of the approaches mentioned above. This has also been observed at different places in this special issue, for example in the contribution by Broekkamp and Van Hout-Wolters.

\section{The Research Needed}

One of the reasons it took so long to bridge the theory-practice divide is that for many decades yet another additional gap existed, namely between the research carried out into teacher development and the work educators did in teacher education or innovation projects. Research into teacher education did reveal the minimal impact of programs, but what actually goes on inside teacher education all over the world remained obscure (Zeichner, 1999). As a result, research has generally been of little practical help to those educators wishing to promote the integration of research and practice (Cochran-Smith \& Zeichner, 2005). Only relatively recently, much more research into teacher education has been carried out from an insider perspective (cf. Anderson \& Herr, 1999). Especially the growth of self-study research by teacher educators may help us to learn more about the details of approaches that teacher educators use, which of these are effective for bridging the gap, and which are not. The educational community can benefit from in-depth analyses of what is happening in teacher preparation or professional development programs in different countries, especially from studies linking program goals with careful analyses of interventions and the effects on teachers, with special attention being paid to the contextual influences of schools. Day (1999) is an excellent example of this kind of perspective in in-service contexts. Such studies may clarify that it is possible to link research and practice in such a way that positive effects can be demonstrated, as Brouwer and 
Korthagen (2005) showed. In short, what is needed is research from an insider perspective into the research - practice gap. In the terminology of Stark and Mandl in this special issue, this would mean integrative research into the theory-practice gap. Only through in-depth studies on the outcomes of various attempts to bridge the gap, may we hope to develop insights on which we can build approaches that really make a difference.

\section{References}

Anderson, G. L., \& Herr, K. (1999). The new paradigm wars: Is there room for rigorous practitioner knowledge in schools and universities? Educational Researcher, 28(5), $12-21,+40$.

Ashton, P. (1996). Improving the preparation of teachers. Educational Researcher, 25(9), 21 -22, 35.

Barone, T., Berliner, D. C., Blanchard, J., Casanova, U., \& McGowan, T. (1996). A future for teacher education. In J. Siluka (Ed.), Handbook of research on teacher education (2nd ed., pp. 1108-1149). New York: Macmillan.

Brouwer, N., \& Korthagen, F. (2005). Can teacher education make a difference? American Educational Research fournal, 42(1), 153-224.

Brown, J. S., Collins, A., \& Duguid, P. (1989). Situated cognition and the culture of learning. Educational Researcher, 18(1), 32-42.

Bullough, R. V. (1997). Practicing theory and theorizing practice in teacher education. In J. Loughran \& T. Russell (Eds.), Purpose, passion and pedagogy in teacher education (pp. 13-31). London/Washington, DC: Falmer Press.

Bullough, R. V., \& Kauchak, D. (1997). Partnerships between higher education and secondary schools: Some problems. Fournal of Education for Teaching, 23(3), 215-233.

Castle, J. B. (1997). Toward understanding professional development: Exploring views across a professional development school. Teachers and Teaching: Theory and practice, 3(2), $221-242$.

Clark, C., \& Lampert, M. (1986). The study of teacher thinking: Implications for teacher education. Fournal of Teacher Education, 37(5), $27-31$.

Cochran-Smith, M., \& Lytle, S. (1993). Insideloutside: Teacher research and knowledge. New York: Teachers College Press.

Cochran-Smith, M., \& Zeichner, K. M. (Eds.). (2005). Studying teacher education: The report of the Panel on Research and Teacher Education. Washington, DC: American Educational Research Association/Mahwah, NJ: Erlbaum.

Darling-Hammond, L. (1994). Professional development schools: Schools for developing a profession. New York: Teachers College Press.

Day, C. (1999). Developing teachers: The challenges of lifelong learning. London/Philadelphia: Falmer Press.

Dewey, J. (1904). The relation of theory to practice in education. In C. A. McMurry (Ed.), The relation between theory and practice in the education of teachers: Third Yearbook of the National Society for the Scientific Study of Education, part 1 (pp. 9-30). Chicago: The University of Chicago Press.

Eraut, M. (1995). Schön shock: A case for reframing reflection-in-action? Teachers and Teaching: Theory and Practice, 1(1), 9-22.

Fenstermacher, G. D. (1994). The knower and the known: The nature of knowledge in research on teaching. Review of Research in Education, 20, 3-56.

Furlong, J., Whitty, G., Whiting, C., Miles, S., Barton, L., \& Barrett, E. (1996). Re-defining partnership: Revolution or reform in initial teacher education? Fournal of Education for Teaching, 22(1), 39-55. 
Hargreaves, A. (1998a). The emotional practice of teaching. Teaching and Teacher Education, 14(8), $835-854$.

Hargreaves, A. (1998b). The emotions of teaching and educational change. In A. Hargreaves, A. Lieberman, M. Fullan, \& D. Hopkins (Eds.), International handbook of educational change (pp. 558-575). Dordrecht/Boston/London: Kluwer.

Hoban, G. F. (2002). Teacher learning for educational change. Buckingham/Philadelphia: Open University Press.

Hoban, G. F. (2005). The missing links in teacher education design: Developing a multi-linked conceptual framework. Dordrecht, The Netherlands: Springer.

Huibregtse, I., Korthagen, F., \& Wubbels, T. (1994). Physics teachers' conceptions of learning, teaching and professional development. International fournal of Science Education, 16(5), $539-561$.

Joram, E., \& Gabriele, A. (1998). Preservice teacher's prior beliefs: Transforming obstacles into opportunities. Teaching and Teacher Education, 14(2), 175-191.

Korthagen, F. A. J. (2004). In search of the essence of a good teacher: Towards a more holistic approach in teacher education. Teaching and Teacher Education, 20(1), 77-97.

Korthagen, F. A. J., Kessels, J., Koster, B., Lagerwerf, B., \& Wubbels, T. (2001). Linking practice and theory: The pedagogy of realistic teacher education. Mahwah, NJ: Lawrence Erlbaum.

Lortie, S. (1975). Schoolteacher: A sociological study. Chicago: University of Chicago Press.

Loughran, J. (2006). Developing a pedagogy of teacher education. London: Routledge.

Loughran, J. J., Hamilton, M. L., LaBoskey, V. K., \& Russell, T. (2004). International handbook of self-study of teaching and teacher education practices. Dordrecht, The Netherlands: Kluwer.

Marton, F., \& Booth, S. (1997). Learning and awareness. Mahwah, NJ: Lawrence Erlbaum.

Marton, F., Dahlgren, L. O., Svensson, L., \& Saljö, R. (1977). Inlärning och omvärldsuppfattning [Learning and conceptions of reality]. Stockholm: Almqvist \& Wiksell.

Nias, J. (1996). Thinking about feeling: The emotions in teaching. Cambridge fournal of Education, 26(3), 293-306.

Robinson, V. M. J. (1998). Methodology and the research-practice gap. Educational Researcher, 27(1), $17-26$.

Schön, D. A. (1983). The reflective practitioner: How professionals think in action. New York: Basic Books.

Showers, B., \& Joyce, B. (1996). The evolution of peer coaching. Educational Leadership, 53(6), $12-16$.

Shulman, L. S. (1998). Theory, practice, and the education of professionals. The Elementary School fournal, 98(5), 511-526.

Stenhouse, L. (1975). An introduction to curriculum research and development. London: Heinemann.

Stofflett, R., \& Stoddart, T. (1994). The ability to understand and use conceptual change pedagogy as a function of prior content learning experience. Fournal of Research in Science Teaching, $31(1), 31-51$.

Tom, A. (1997). Redesigning teacher education. Albany, NY: State University of New York.

Wenger, E. (1999). Communities of practice: Learning, meaning and identity. Cambridge, UK: Cambridge University Press.

Wideen, M., Mayer-Smith, J., \& Moon, B. (1998). A critical analysis of the research on learning to teach: Making the case for an ecological perspective on inquiry. Review of Educational Research, $68,130-178$.

Wubbels, T. (1992). Taking account of student teachers' preconceptions. Teaching and Teacher Education, 8(2), 137-149.

Zeichner, K. (1999). The new scholarship in teacher education. Educational Researcher, 28(9), $4-15$. 